\title{
Battery consumption estimation methodology for electric unmanned aerial systems
}

\author{
E. Rodríguez-Novillo and A. Sanchez-Carmona (iD
}

Aircraft and Spacecraft, ETS Ingeniería Aeronáutica y del Espacio, Universidad Politécnica de Madrid, Madrid, 28040, Spain Email: alejandro.sanchezc@upm.es

Received: 12 May 2021; Revised: 7 December 2021; Accepted: 12 January 2022

Keywords: brushles motors; battery consumption; UAS; RPAS

\begin{abstract}
This study presents a methodology to estimate the battery consumption of an electric powerplant, based on brushless motors, typically used in light unmanned aerial systems. The methodology models brushless motors through an equivalent circuit obtained from their dynamic behaviour. Propellers' data are taken from an experimental database. Furthermore, a variable speed controller efficiency is considered in the methodology. All the parameters involved in the model are adjusted by minimising the mean quadratic error of measurements taken in both direct and alternating currents. This model allows designers to predict energy consumption, also if any element of the powerplant changes, such as battery or propeller. Thus, it is useful for selecting the best powerplant for an actual RPAS operation. The results obtained to predict the current consumption of several electric powerplants show a coefficient of determination higher than 0.96 . Finally, the methodology is validated by means of a case study of an actual RPAS, where the best powerplant is selected in terms of endurance.
\end{abstract}

\section{Nomenclature}

$\begin{array}{ll}C_{D O} & \text { zero-lift-drag coefficient } \\ C_{D \alpha 1} & \text { first order derivative of drag coefficient with respect of attack angle } \\ C_{D \alpha 2} & \text { second order derivative of drag coefficient with respect of attack angle } \\ C_{L O} & \text { zero angle-of-attack lift coefficient } \\ C_{L \alpha} & \text { lift-curve slope } \\ C_{p} & \text { power coefficient } \\ C_{T} & \text { thrust coefficient } \\ D & \text { propeller diameter } \\ e & \text { electromotive force in three-phase three-wire star circuit } \\ E & \text { electromotive force in monophase equivalent circuit } \\ E M & \text { empty mass } \\ I_{A C} & \text { alternating current } \\ I_{D C} & \text { direct current } \\ I_{m} & \text { line current in Ref. [32] } \\ J & \text { advance ratio } \\ K_{E} & \text { electromotive force constant } \\ K_{L} & \text { inductance constant } \\ K_{Q} & \text { torque parameter } \\ K_{r} & \text { torque losses parameter } \\ K_{v} & \text { voltage constant } \\ K_{\eta 0} & \text { constant parameter in efficiency factor } \\ K_{\eta I} & \text { alternating current parameter in efficiency factor } \\ K_{\eta \omega} & \text { angular velocity parameter in efficiency factor } \\ & \end{array}$




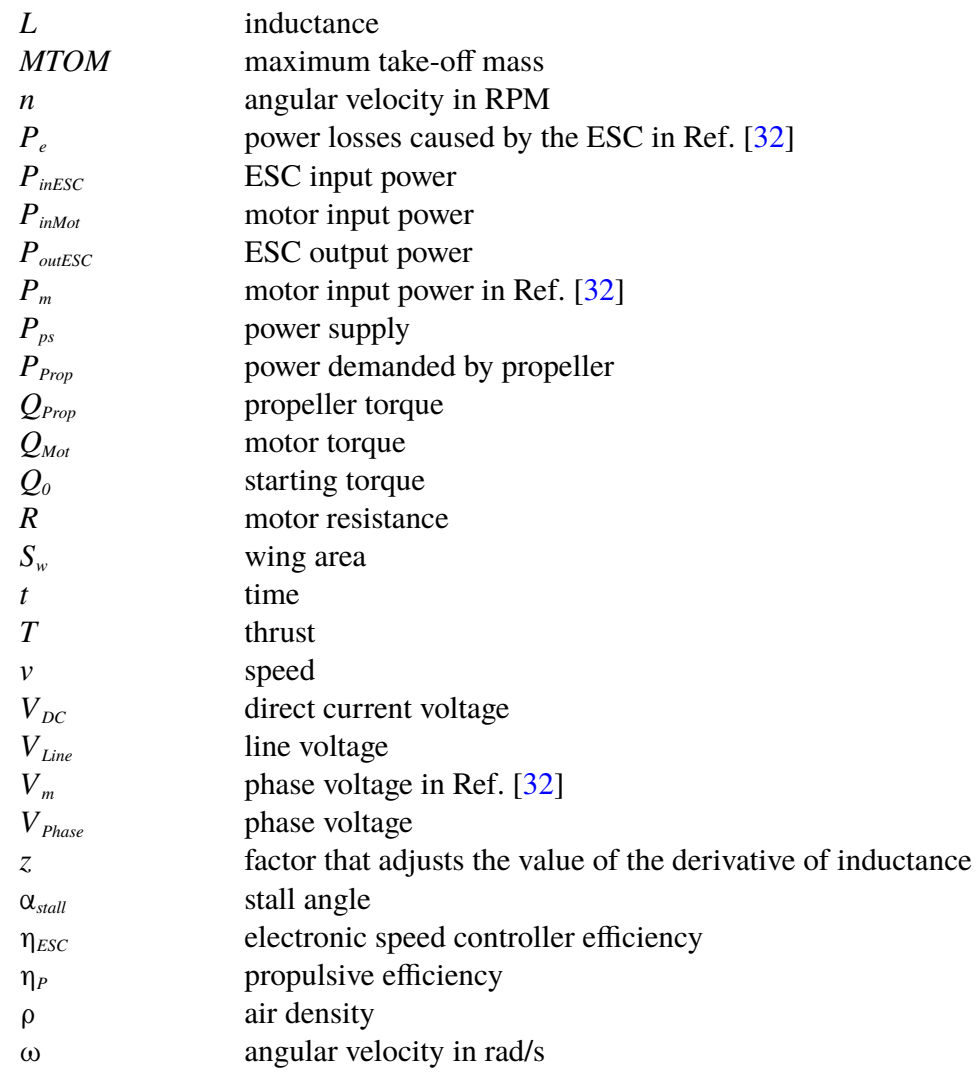

\subsection{Introduction}

The remoted piloted aircraft system (RPAS), also called unmanned aerial system (UAS), market is undergoing continuous expansion. In fact, the forecast for 2024 is that the commercial drone market will grow to around 43 billon USD, with an annual growth rate of over $20 \%[1,2]$. This expected growth is due to the companies finding several advantages to incorporate drones in their productive processes, such as saving costs and time or even increasing the safety. It is true that the COVID19 pandemic has had a negative short-term impact in the capacity of companies to invest in this novel technology; however, it is expected that the companies promote the automatisation of their processes, and here, drones could have a relevant role. From the standpoint of commercial applications carried out by drones, the market is focused on light platforms, which are equipped with electric propulsion systems [3-9].

This market expansion is conditioned by the regulatory framework. At American level, the commercial applications of light RPAS, under $25 \mathrm{~kg}$ of MTOM (Maximum Take-Off Mass) are regulated by FAR Part 107 [10]. This regulation does not allow to overfly people who are not directly involved in the aircraft operation. More risky operations could need certification or additional approvals. The expansion of this market at European level is conditioned by the new regulatory framework published by the European Commission. This regulation supposes that the European Commission is going to take the control, detrimental to the rules of the National Authorities in force nowadays. This path planning begins at $1^{\text {st }}$ January 2021 and expects to finish in 2023, with the full control of the drone regulations by the European Authority [11]. The regulation establishes three categories of operation according to the risk level: open, specific, and certified. Open category regulates operation of light drones, under $25 \mathrm{~kg}$ of MTOM, but it imposes hard constraints to the operation to guarantee a low level of risk. In fact, the RPAS are not allowed to overfly people's meetings or carry out autonomous operations. Specific and certified categories encompass higher risk operations, so the requirements to the operator and the aircraft are 
more demanding. The main conclusion extracted of this regulatory framework is that the most interesting applications for RPAS, which correspond to those with higher associated risk, will probably need a deeper and more accurate knowledge of the aircraft in order to convince the authority that the operation is safe enough.

Focusing on the systems of those light drones, the electric propulsion system is usually made up of LiPo batteries, electronic speed control (ESC) devices, brushless direct current (BLDC) motors, and fixed-pitch propellers. Research about these elements in an isolated way has been performed in the state of the art. From the standpoint of lithium-polymer batteries, there are studies that try to improve the performance of them $[12,13]$. Furthermore, some other works propose more efficient strategies to control or monitor the aircraft optimising the energy consumption [14, 15]. In the field of propellers for drones, several research studies are centered on modelling and estimating its behaviour at low Reynolds numbers [16-18]. Moreover, there are studies that analyse the potential benefits of using variable pitch propellers in small RPAS [19]. From the standpoint of the electronic speed controller, there are some studies that try to evaluate and also model its efficiency [20,21]. Finally, BLDC motors, after all, are a kind of electromechanical system. Thus, several models can be found in the state of the art that describe, with different levels of complexity and accuracy, the behaviour of these motors [22, 23].

The most common design strategy of the propulsion system of current commercial RPAS is based on manufacturer experience [24, 25], simple models [26] and/or commercial software [27-29]. These simple models are utilised to estimate the powerplant behaviour in an early stage of the design process. Nevertheless, they do not have accuracy enough to undertake a comparative analysis to select the better combination of the elements that make up the propulsion system, as it has been checked through experimental tests undertaken in this current work. On the other hand, the commercial software available to estimate the performances of electric propulsion systems for RPAS is also based on simple models, which do not reproduce the actual behaviour of the motor or the whole system, when comparing with real tests. For solving this drawback, one possibility is to test the whole system in several conditions (charge level of the battery, wind speed, etc.) and use this information to adjust a model of that combination of elements [30-32]. This solution is powerful from the point of view of the control of the aircraft. However, it has the problem that it is necessary to perform a new a set of tests every time that the designer wants to change one element of the propulsion system. Another possibility to improve the accuracy of the simplest models is to use a more complex one for which it is necessary to estimate a set of parameters. The approach to this kind of models is usually theoretical. The parameters are determined based on specifications given by the manufacturers, such as internal resistance or the voltage constant, and on some hypothesis that simplifies the problem, like considering that the ESC dissipates a constant power $[33,34]$. The downside of this strategy is that the manufacturers that sell these products, concretely BLDC motors, come from making model aircrafts. Thus, the demanding level required for this purpose differs from the current use that these toys are taking. Even more, if these products need to be used for more risky applications, which would require to operate in the specific category, in EU case, or beyond Part 107, in US, the requirements will be even harder. To sum up, it would not be desirable to build a model exclusively based on the manufacturer's data, because the purpose of those data is not to reproduce the behaviour of the system, it is just to know the performance in a qualitative way. Finally, another possible strategy to design an electric propulsion system for drones is to base it on statistical correlations in order to estimate the weight and the set of parameters necessary to build the powerplant model [35]. This methodology has the disadvantage that the parameters do not correspond with any real system of the market, so, it could not be possible to perform a comparative study between several combinations of the system's elements, as it happens for the simplest powerplant models exposed previously.

Therefore, the main objective of this work is to combine the benefits of the two usual strategies found in the state of the art. The idea is to use a model that is accurate enough to predict the battery consumption, but, on the other hand, has the flexibility to allow the designer to change elements of the system, such as the battery or the propeller, without having to recalculate all the parameters involved in the model. This objective is born because the performance objectives of a RPAS designer can be 


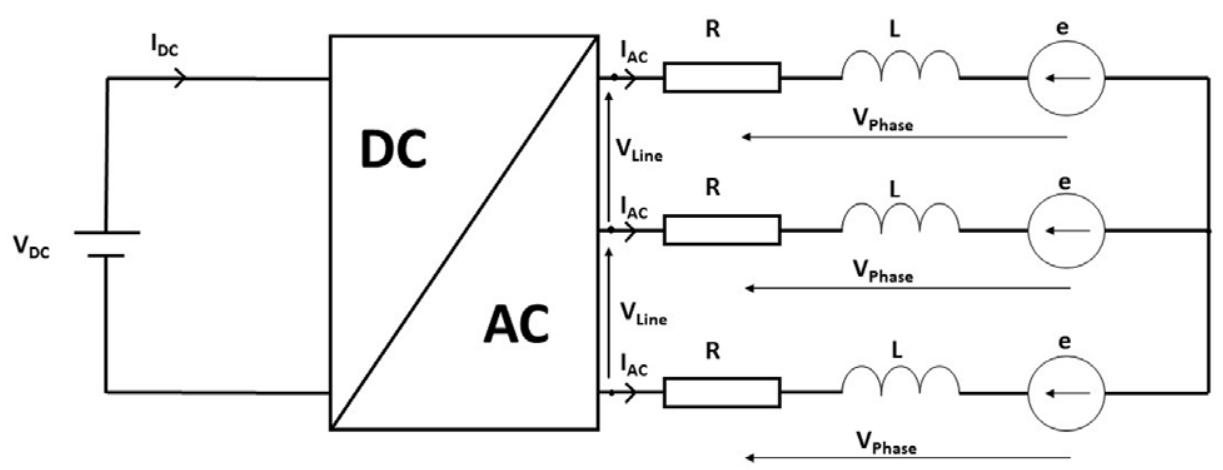

Figure 1. Equivalent dynamic brushless DC motor circuit.

reached through several combinations of electric propulsion systems. Hence, the proposed methodology could give the possibility to analyse in a simpler way several combinations and try to find the best one from the standpoint of energy consumption. To reach this goal, a physical-mathematical model of the BLDC motor has been chosen from the state of the art, with some particular modifications. Because the objective of this work is focused on finding the best combination of the elements that make up the propulsion system, and not centred on the control of it, the selected model does not retain non-steady effects. All the parameters involved in that model have been determined experimentally, without any manufacturer's data. For doing that, several combinations of motor and propellers have been performed. In addition, in order to avoid the discharge effect of the battery, a power supply has been used. A sweep in several voltage values has been performed for analysing its effect. Finally, the ESC allows the user to adjust the percentage of power supplied to the motor by the thrust command. Thus, for each supply voltage, a sweep on thrust command has been carried out. Once all these conditions have been tested, all data have been compiled and the parameters have reached their corresponding values, the model will be prepared to predict the behaviour of the powerplant for any other propeller or any other voltage supply.

Thus, the paper is organised so that first the chosen mathematical model is presented. After that, there is a section dedicated to the methodology, where it is going to be explained how the parameters involved in the model have been determined. Then, the results section exposes the accuracy of the presented methodology. And, finally, a case study has been performed in order to select a propulsion system that reduces the energy consumption of an aircraft.

\subsection{Mathematical Model for BLDC Motor}

The mathematical model selected for performing this study is based on the dynamic model of a brushless DC motor, shown in Fig. 1. The schematic includes all the elements that form the powerplant: direct current battery, electronic speed controller, which converts direct current to alternating current, and three-phase motor. The motor is made up of a resistance, $R(\Omega)$, an inductance, $L(H)$, and an electromotive force, $e(V)$ [22]. It is important to highlight that this model is going to be used in steady state, because the work is not focused on the dynamic behaviour nor the control of the electric propulsion system.

Following classical guidelines for electromechanical systems, it is possible to establish an equivalent electric circuit where the variables of the electric circuit behave exactly as the analogous variables of the electromechanical system. In the case of BLDC motor, the equivalent circuit is represented in Fig. 2 [34].

This analog corresponds to an equivalent circuit of a three-phase three-wire star configuration. Thus, the real component of the impedance is the resistance $R$ and the induced part is the inductance $L$. The alternating current that flows by this analog coincides with the line current of the original schematic and, because the load is balanced, it is equal to phase current $I_{A C}$. On the other hand, the voltage applied to this analog corresponds to phase voltage, $V_{\text {Phase }}$, which is $V_{\text {Line }} / \sqrt{ } 3$. 


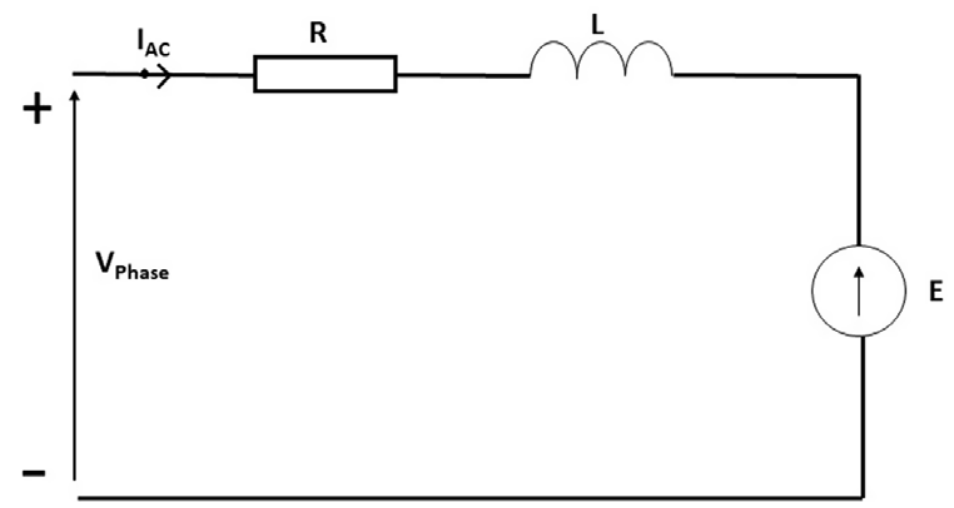

Figure 2. Monophase equivalent circuit of a BLDC motor. $R$ is the motor resistance; $L$ is the inductance and $E$ is the electromotive force and $V_{\text {Phase }}$ is phase voltage.

From this analog, it is possible to establish Equation (1), that models the motor's behaviour.

$$
V_{\text {Phase }}=I_{A C} R+E+L \frac{d I_{A C}}{d t}
$$

The electromotive force (emf), $E$, can be modelled as is indicated in Equation (2), where $K_{E}$ is the emf constant and $\omega$ is the angular velocity of the motor measured in $\mathrm{rad} / \mathrm{s}$.

$$
E=K_{E} \omega
$$

The last term included in Equation (1) can be approximated as it is indicated in Equation (3), where $K_{L}$ is the inductance constant and $z$ is a factor that adjusts the value of the derivative.

$$
L \frac{d I_{A C}}{d t} \cong K_{L} \omega I_{A C}^{z}
$$

Substituting Equations (2) and (3) in Equation (1), it is possible to reach the expression represented in Equation (4).

$$
V_{\text {Phase }}=I_{A C} R+K_{E} \omega+K_{L} \omega I_{A C}^{z}
$$

Analysing the magnitude order of the terms that appears in Equation (4) for typical values of the constants, it is possible to conclude that left-hand side term is of unity order, resistance term is 0.1 order, emf term is unity order and inductance term has order of 0.001 . Therefore, it is justified to neglect the last term, resulting in the final expression for estimating phase voltage included in Equation (5). To sum up, it is necessary to obtain the values of two constants, $R$ and $K_{E}$, to model the behaviour of phase voltage.

$$
V_{\text {Phase }}=I_{A C} R+K_{E} \omega
$$

From that equation it is possible to obtain input power to BLDC motor in Equation (6), which will coincide with the output power of the ESC. It is supposed that there are no losses between ESC and motor.

$$
P_{\text {inMot }}=P_{\text {out ESC }}=3 V_{\text {phase }} I_{A C}=3\left(I_{A C} R+K_{E} \omega\right) I_{A C}
$$

ESC efficiency factor is defined as the quotient between input power to BLDC motor and direct current power provided by power supplier, as Equation (7) describes.

$$
\eta_{E S C}=\frac{P_{i n M o t}}{P_{p s}}=\frac{3 V_{P h a s e} I_{A C}}{V_{D C} I_{D C}}
$$

This efficiency factor can be modelled through different strategies that can be found in the literature [21-33]. The studies show that the efficiency factor can be modelled as constant or as depending on 
current and voltage, which is analogous to current and angular speed. So, to simplify these dependencies, in this work it has been decided to model this factor as it is indicated in Equation (8).

$$
\eta_{E S C}=\frac{I_{A C}}{K_{\eta I}}+\frac{\omega}{K_{\eta \omega}}+K_{\eta 0}
$$

Thus, these new three constants, $K_{\eta I}, K_{\eta \omega}$, and $K_{\eta 0}$, must be determined and added to the corresponding motor ones. Through Equations (7) and (8) it is possible to obtain the power provided by power supplier and, consequently, an estimation of the direct current consumed by it, just dividing power by supplied voltage, $V_{D C}$.

In order to close the model, the output motor power needs to be determined. First, torque generated by BLDC motor depends on the current through Equation (9), which is based on equation that describes the steady behaviour of the motor but including the dependency of angular speed [34]. In that equation, $K_{Q}$ is called torque parameter, $K_{r}$ represents torque losses and $Q_{0}$ refers to starting torque. Once motor torque is determined, just multiplying it by angular velocity, output motor power is obtained.

$$
Q_{M o t}=K_{Q} I_{A C}+K_{r} \omega-Q_{0}
$$

To sum up, to model the behaviour of the electric propulsion system used to have light RPAS, it is necessary to estimate the following eight parameters: $R, K_{E}, K_{\eta I}, K_{\eta \omega}, K_{\eta 0}, K_{Q}, K_{r}$, and $Q_{0}$.

\subsection{Methodology}

The objective is to estimate the constants needed to build the BLDC motor model. Analysing the equations presented in previous section, there are some independent variables that should be measured in order to determine the eight parameters on which the model depends. These magnitudes can be arranged in electric, dynamic, and cinematic variables. Among the electric magnitudes there are voltage supply, direct current supply, line voltage, and line current. The dynamic variables include torque and thrust. Finally, it is necessary to measure the angular velocity of the motor.

All these magnitudes, except for torque, are going to be measured by means of a test bench. To estimate torque, some tests' results have been taken from Illinois' database [17]. The tests must be performed in the same conditions as those in which tests were performed in Illinois' database to be possible to take torque's results as if they have been measured with the test bench developed in this work.

Once all these magnitudes are measured, or estimated, in several conditions, the goal is to infer the eight parameters by an optimisation process. The idea is to minimise the mean squared error associated to those equations in which these eight parameters are involved, when comparing the results obtained through the mathematical model presented former and the measurements taken with the test bench. Following sections describe the test bench, how torque is obtained from Illinois' database and which technique has been used to minimise the mean squared error. Finally, once the parameters have been determined, an explanation of how this model can be used to estimate the battery consumption of an electric RPAS is undertaken.

\subsection{Test bench}

To perform the measurements, a test bench has been built following the schematic presented in Fig. 3 . The power supplier directly gives the voltage supply. The power supplier is the model RM-LPS130S, which allows to give voltage from 0 to $15 \mathrm{~V}$ with a ripple of $5 \mathrm{mV}$. Between the power supplier and the ESC, the direct current is measured by means of a wattmeter. Its resolution is $\pm 0.01 \mathrm{~A}$ and can measure until 100A. After the current passes through the ESC, it is converted to alternating current and with the use of a clamp meter and a voltmeter, the line current and the phase voltage can be measured, respectively. The clamp meter has an accuracy of $\pm 2 \%$ of reading to 5 decimal places, and the voltmeter of $\pm 1 \%$ of reading to 3 decimal places. The ESC is controlled by means of a control station via the 


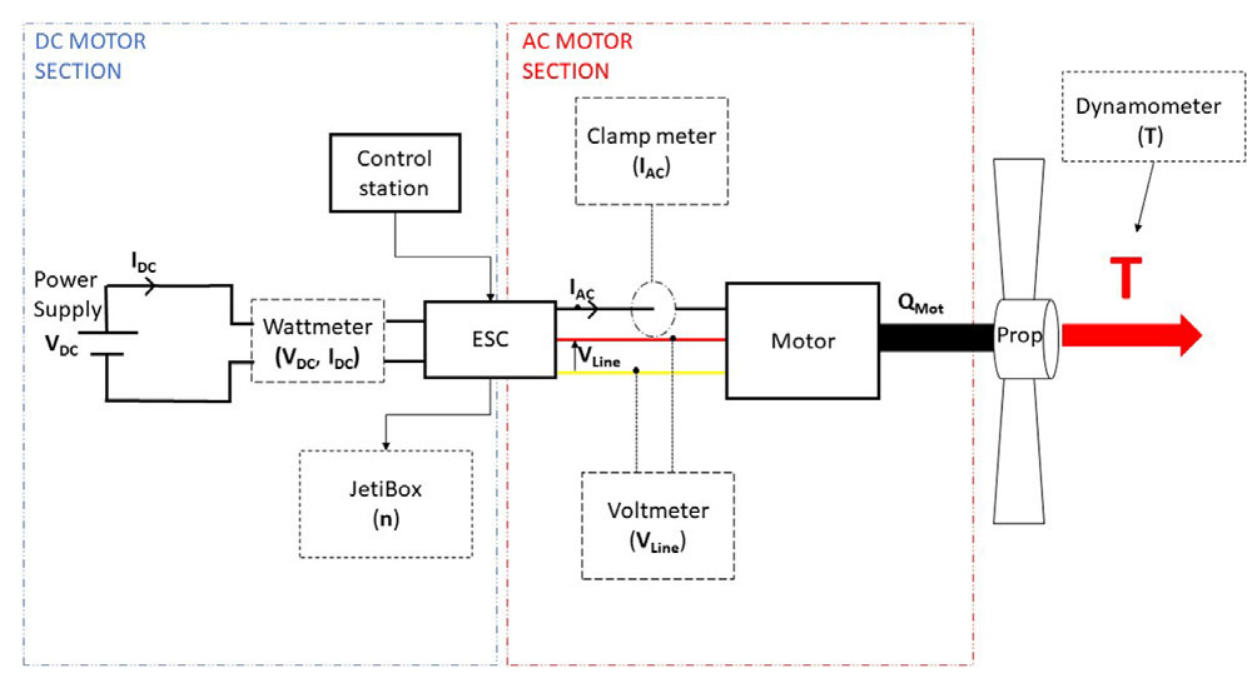

Figure 3. Test bench schematic.

throttle stick, that adjusts the energy from the power supplier and, consequently, the angular velocity of the motor. This angular velocity is measured through an element called Jetibox, which monitors the PWM's (Pulse Width Modulation) frequency. Propeller's rotation generates thrust, which is measured by dynamometer with an accuracy of $\pm 125 \mathrm{~g}$.

The test bench presents a drawback, due to the fact the motor torque can't be measured. Hence, the torque constants seen in the previous Equation (9) cannot be determined. Therefore, it is decided to look for another method in which to calculate the torque and determine the constants. The process developed is discussed in the next section.

\subsection{Propeller's performance}

The goal is to estimate the torque demanded by the propellers depending on the angular velocity. Assuming that the torque given by the motor is the same as that demanded by the propeller, it is possible to solve the inconvenience of not measuring the torque in the test bench. Therefore, some experimental tests are going to be considered. These tests were developed in the Illinois University for small propellers usually installed in light RPAS [17]. This study encompasses results for 79 propellers of several manufacturers, diameters, and pitches, such as thrust and power coefficients, for a set of angular velocities and advance ratio, $J$. Using the nomenclature exposed in former sections, the expressions needed for building the BLDC model are Equations (10), (11), (12) and (13), where $P_{\text {Prop }}$ is the power demanded by the propeller, $D$ is its diameter, $\mathrm{T}$ is the thrust generated and $n$ is the angular velocity expressed in revolutions per second.

$$
\begin{aligned}
c_{P} & =\frac{P_{\text {Prop }}}{\rho n^{3} D^{5}} \\
Q_{\text {Mot }} & =\frac{c_{p} n^{3} D^{5}}{\omega} \\
J & =\frac{V}{n D} \\
c_{T} & =\frac{T}{\rho n^{2} D^{4}}
\end{aligned}
$$



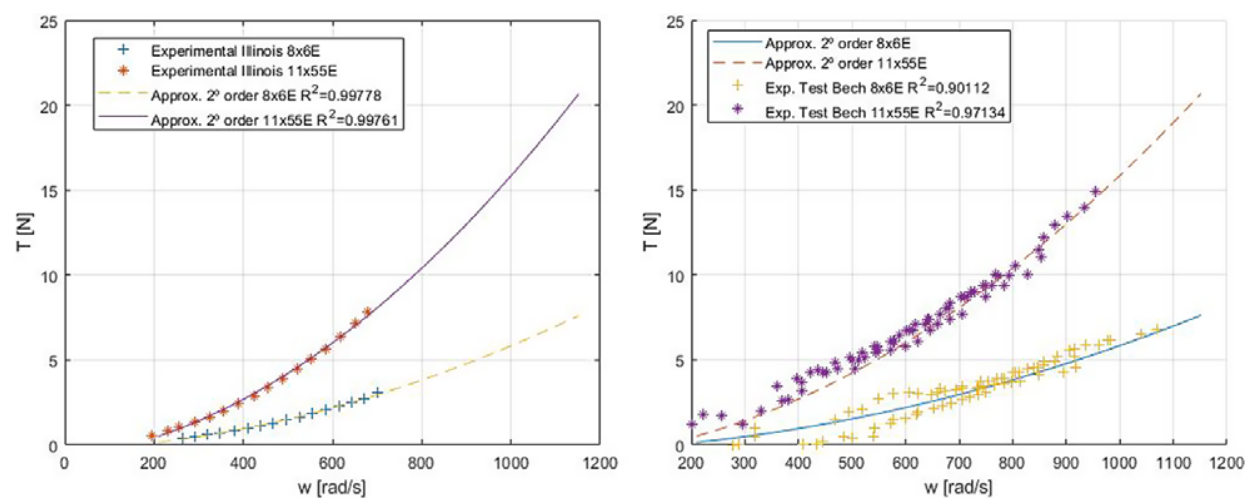

Figure 4. Second order polynomial approximation of Illinois' results for APC 8x6E and APC 11x55 propellers (left) and comparison between the approximation and the results measured in the test bench (right).

The process consists of taking the data from Illinois' tests as they were taken in the test bench built in this study. In order to allow this equivalence, it is necessary to prove that the results in terms of thrust are similar to those obtained in Illinois' test. It has been decided to do this checking with the following propellers: APC 8x6E and APC 11x5.5E. The drawback is that the tests driven in Illinois' study were focused on lower angular velocities. Thus, it has been decided to extrapolate the results through a second order polynomial, represented in Fig. 4. These curves have been obtained by means of Equation (13), using air density of the lab where the tests have been performed. As the graph shows, the approximation is quite accurate, with a coefficient of determination, $R^{2}$, higher than 0.99 in both cases. Therefore, once the polynomial approximation is considered as valid, it is possible to compare the results of thrust measured in the test bench with the results of thrust extrapolated from Illinois' data. Again, Fig. 4 shows the correlation coefficient obtained when comparing the measured points with the approximated curve. In this case, the values are higher than 0.90 for both propellers. Thus, as a first approximation, it is possible to consider the conditions in which the tests have been performed as equivalent to those in which the Illinois' database were built. Consequently, torque data included in Illinois' database can be taken in order to estimate the parameters of the BLDC model.

\subsection{Estimation of model's parameters}

The built model in this study depends on eight parameters, as was concluded formerly. The way to estimate the values for these parameters is by means of a multivariate optimisation. The idea is to use the data measured, or taken from Illinois' database, as an input of the model and try to obtain the combination of all these parameters that better adjust to the experimental information. The algorithm chosen for this task is called Levenberg-Marquardt [36, 37]. This algorithm behaves like a steepest descent approach when the iteration point is far from the minimum and like a Gauss-Newton method when it is close to the minimum. Thus, this technique trades off the best characteristics of those two algorithms to solve a wider range of problems [38].

\subsection{Energy consumption estimation for RPAS' performance}

As explained in the Introduction, the objective of this study is to estimate the current consumption of the powerplant in a steady condition. In order to reach this objective, first of all it is necessary to know the aerodynamic and weight characteristics of the RPAS. By means of choosing the steady manoeuver to be analysed, the thrust of the powerplant and the speed are fixed. Thus, the powerplant must develop the fixed thrust at the selected aircraft speed. These two constraints are input data to the propeller. For each propeller model, there is one combination of angular velocity, propulsive efficiency $\left(\eta_{P}\right)$ and torque that 
Table 1. Parameters for three BLDC motors

\begin{tabular}{llccc}
\hline Parameter & Units & AXI 2820/12 & AXI 2826/12 & AXI 4120/14 \\
\hline$K_{E}$ & $\mathrm{mV} \cdot \mathrm{s} / \mathrm{rad}$ & 4.21 & 5.4 & 6.6 \\
$R$ & $\mathrm{~m} \Omega$ & 23.7 & 25.9 & 17.4 \\
$K_{\mathrm{n} I}$ & $\mathrm{~A}$ & 351.2 & 721.4 & 398.7 \\
$K_{\eta \omega}$ & $\mathrm{rad} / \mathrm{s}$ & 4,327 & 3,447 & 4,420 \\
$K_{\mathrm{n} 0}$ & - & 0.6787 & 0.7577 & 0.7068 \\
$K_{Q}$ & $\mathrm{~N} \cdot \mathrm{m} / \mathrm{A}$ & 0.0102 & 0.0119 & 0.0097 \\
$K_{r}$ & $\mathrm{mN} \cdot \mathrm{m} \cdot \mathrm{s} / \mathrm{rad}$ & -0.00132 & 0.029 & 0.155 \\
$Q_{0}$ & $\mathrm{~N} \cdot \mathrm{m}$ & -0.0103 & 0.0149 & 0.0557 \\
\hline
\end{tabular}

corresponds to the operation point, which develop that thrust at that aircraft speed. It is supposed that between propeller and motor there are no losses, because the powerplant is direct drive.

Once torque and angular velocity are known, it is possible to determine the line current through Equation (9). After that, Equation (5) gives an estimation of the phase voltage in those conditions. As ESC efficiency factor is a function of line current and angular velocity, Equation (8), it is possible to estimate its value. Attending to Equation (7), if the voltage provided by the battery, or the power supplier, is known, direct current necessary to operate in that point can be determined. Finally, the energy consumed by the battery if it remains performing the manoeuver for $t$ seconds, can be estimated by multiplying direct current by the time. This described procedure is represented in Fig. 5.

\subsection{Model Validation}

\subsection{Comparison with test bench measurements}

The methodology presented in this work has been applied to three BLDC motors, which are AXI 2820/12, AXI 2826/12 and AXI 4120/14. The results for the eight parameters after the optimisation process are included in Table 1.

To analyse the accuracy of the methodology, a comparative study between the variables measured with the test bench and the same variables estimated through the model is going to be performed. The motor AXI 2826/12 is going to be the reference case. This motor has been tested with four APC propellers: $8 \times 6 \mathrm{E}, 11 \times 5.5 \mathrm{E}, 12 \times 6 \mathrm{E}$ and $14 \times 7 \mathrm{E}$. In addition, for each propeller, the following four supply voltages have been measured: $11 \mathrm{~V}, 12 \mathrm{~V}, 13 \mathrm{~V}$ and $14 \mathrm{~V}$. For each voltage, a sweep has been performed in terms on thrust stick, from $0 \%$ to $100 \%$.

Figure 6 shows a comparison between experimental measures, denominated as Exp. in the legend, and estimated results, called as Approx. in the legend, for Equation (5). The legend includes the coefficient of determination for all the estimated results, when compared with the measured ones [39]. It is possible to see that all of them are above 0.97 , which supposes a very good approximation.

The next equation to be checked is Equation (8), to validate if the hypothesis of considering the ESC efficiency factor dependent on angular velocity and line current improves the classical hypothesis of considering it as a constant value. Figure 7 represents values obtained for this factor from the measures taken in the test bench, just in case that the line current is equal to 5A, to make the figure clearer. There, it is possible to see that coefficient of determination is considerably slower when the efficiency factor is considered as constant than dependent on angular velocity. This behaviour is repeated for all values of line current. Thus, despite coefficient of determination being lower for the approximation presented in this work, it is much better than considering it as a constant value.

Following the checking process, Fig. 8 depicts the accuracy of the power given by the power supplier as a function of the angular velocity. As before, the points represent the measured variables and the curves the estimations driven by the methodology presented in this study. The coefficients of determination obtained for the four propellers included in the figure are clearly higher than 0.97 . The next and last step is to check direct current. Figure 9 represents the measures taken for the four propellers and a 


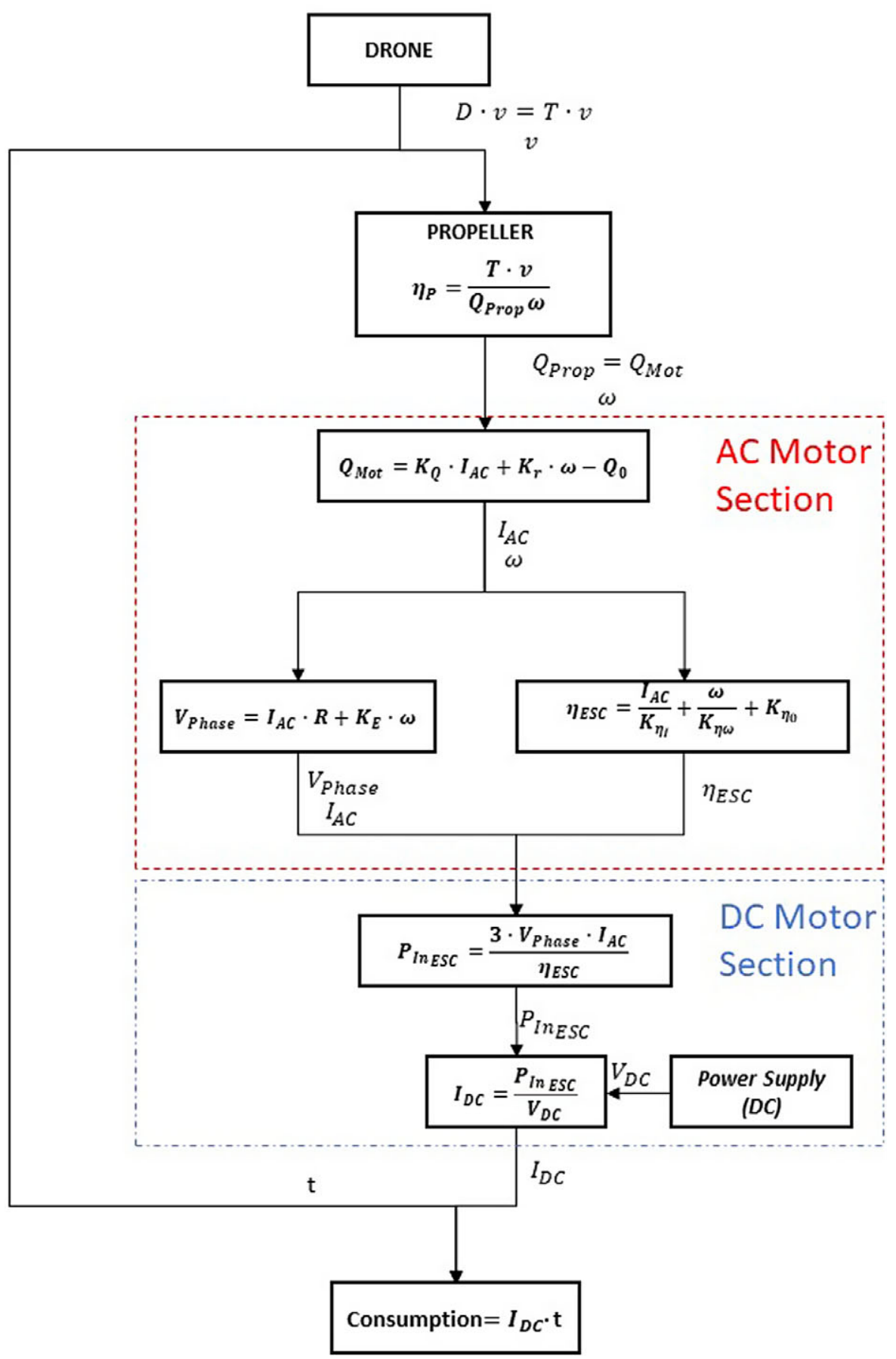

Figure 5. Schematic of procedure to estimate energy consumption of electric light RPAS.

supplied voltage of 13V. Once again, experimental points are called Exp. in the legend, and estimated curves are Approx. Analysing the obtained coefficients of correlation, all of them are above 0.96. Thus, it is possible to conclude that the methodology presented in this work can fit the energy consumption of an electric powerplant for light aircraft with high accuracy. 


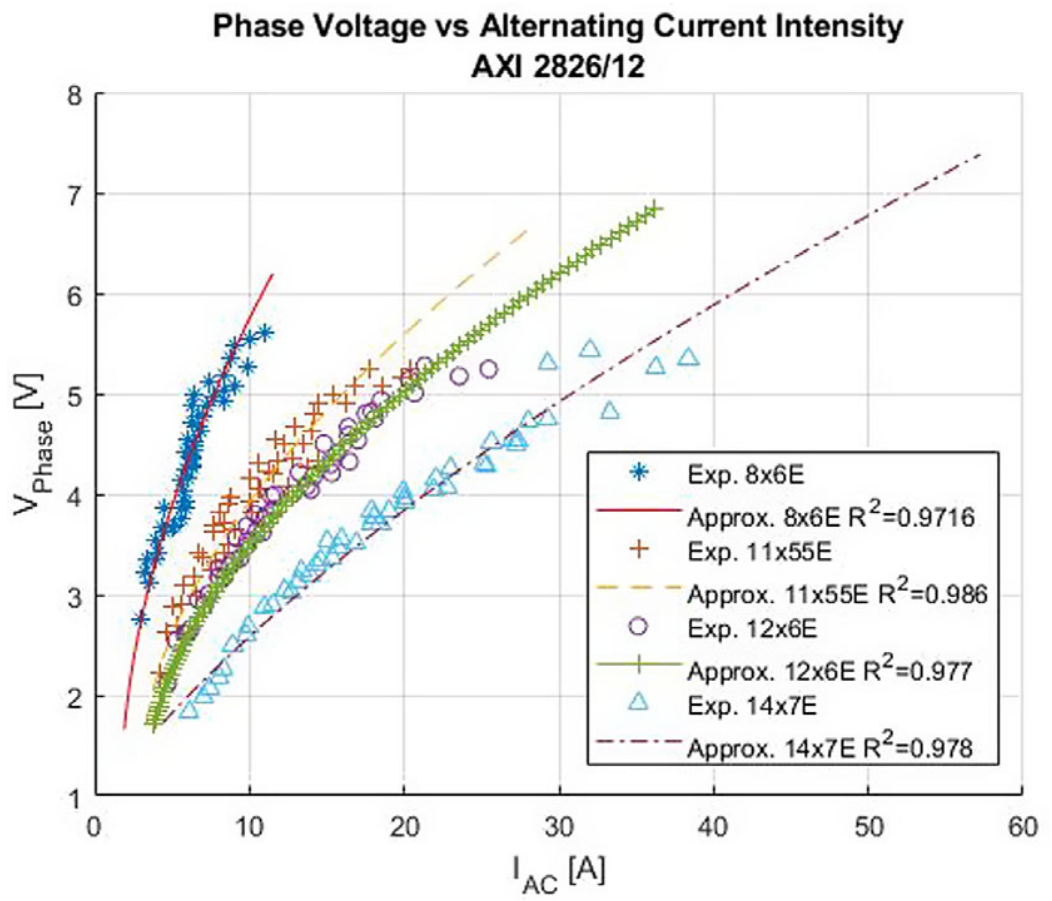

Figure 6. Phase voltage versus alternating line current for AXI 2826/12 motor with four different propellers, comparing experimental and estimated results.

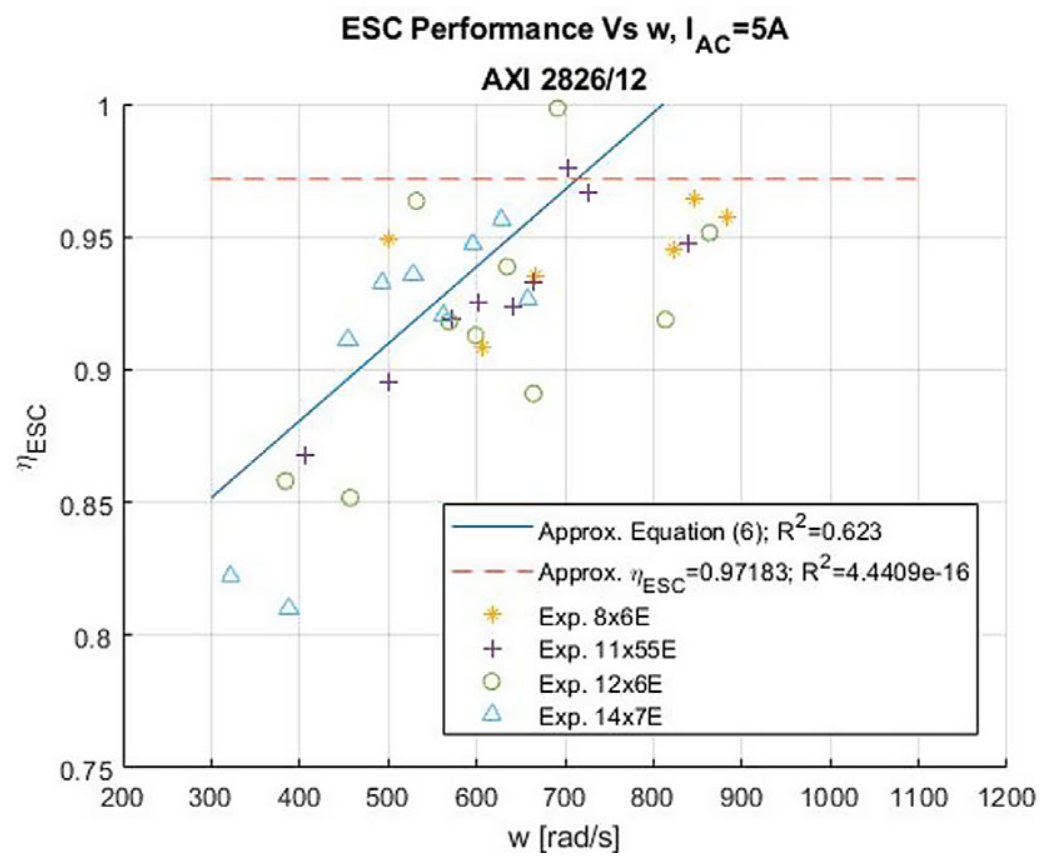

Figure 7. ESC efficiency factor versus angular velocity with a line current equal to 5A for AXI 2826/12. 


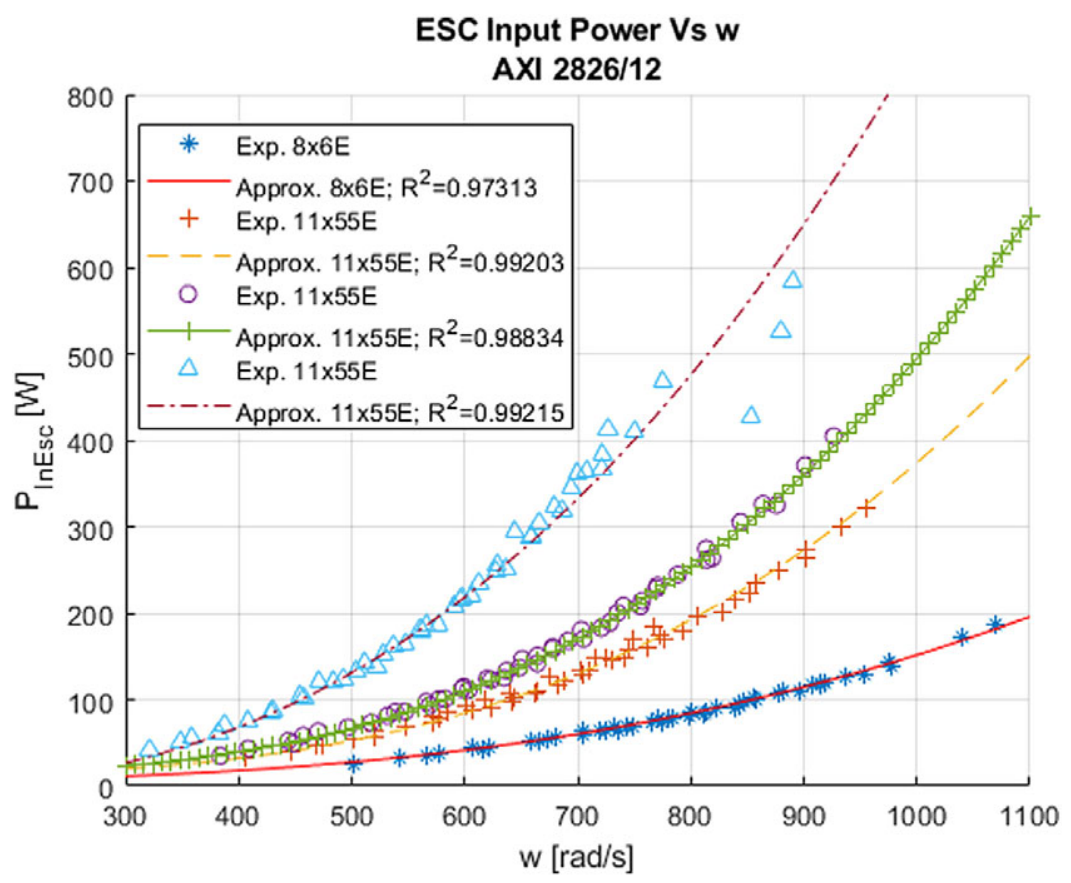

Figure 8. Input power to ESC versus angular velocity for AXI 2826/12.

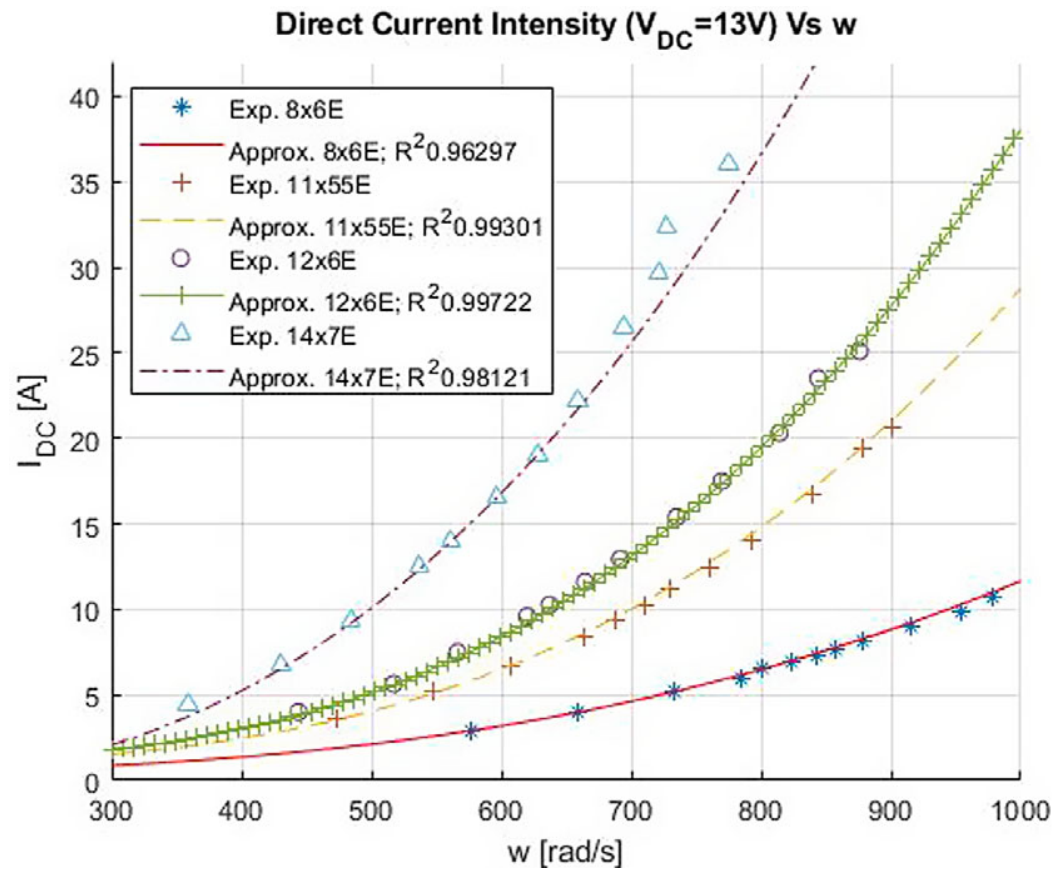

Figure 9. Direct current versus angular velocity at $13 \mathrm{~V}$ of supplied voltage for AXI 2826/12. 
Table 2. Accuracy comparison between reference methodology and the developed model

\begin{tabular}{|c|c|c|c|c|c|c|}
\hline & \multicolumn{2}{|c|}{ AXI 2820/12 } & \multicolumn{2}{|c|}{ AXI 2826/12 } & \multicolumn{2}{|c|}{ AXI 4120/14 } \\
\hline & Reference & Model & Reference & Model & Reference & Model \\
\hline Average $I_{A C}$ error [\%] & 17.04 & 3.78 & 18.04 & 3.83 & 33.16 & 3.58 \\
\hline Average $V_{\text {Phase }}$ error [\%] & 22.23 & 2.42 & 21.34 & 2.63 & 28.94 & 1.28 \\
\hline
\end{tabular}

\subsection{Comparison with other methodologies}

This section tries to compare the accuracy of the methodology proposed in this study with one of the most similar methods found in the state of the art [33]. The idea is to analyse which model fits better to the experimental results measured by means of the test bench. This checking process starts from the measured values of direct current and supplied voltage for each angular velocity. From this data, both models are going to be driven to estimate line current and phase voltage. First of all, Equation (14) is the expression to estimate line current, called $I_{m}$, in Ref. [33], where $P_{e}$ represents the power losses caused by the ESC as a $15 \%$ of the supplied power, $K_{v}$ and $R$ are taken from the manufacturer's datasheet, as the reference indicates.

$$
I_{m}=\frac{-\frac{n}{K_{v}}+\sqrt{\left[\frac{n}{K_{v}}\right]^{2}-4 R\left[P_{e}-V_{D C} \cdot I_{D C}\right]}}{6 R}
$$

The input motor power, $P_{m}$, is represented in Equation (15) and the phase voltage, $V_{m}$, in Equation (16).

$$
\begin{gathered}
P_{m}=V_{D C} I_{D C}-P_{e} \\
V_{m}=\frac{P_{m}}{3 I_{m}}
\end{gathered}
$$

On the other hand, instead of taking the parameters from the manufacturer's datasheet, making use of the equations presented in this study, the corresponding line current equation is Equation (17), and, after that, phase voltage can be estimated through Equation (5).

$$
I_{A C}=\frac{-\left[3 K_{E} \omega-V_{D C} \cdot \frac{I_{D C}}{K_{\eta_{I}}}\right]+\sqrt{\left[3 K_{E} \omega-V_{D C} \cdot \frac{I_{D C}}{K_{\eta_{I}}}\right]^{2}+12 R \cdot V_{D C} \cdot I_{D C}\left[\frac{\omega}{K_{\eta_{\omega}}}+K_{\eta_{0}}\right]}}{6 R}
$$

Now, it is possible to estimate line current obtained through the two methods proposed and compare them with the measures performed in the test bench. Analogously, it is possible to drive a comparison for phase voltage. Table 2 shows the average error obtained when comparing estimated magnitudes with the measured ones. Columns denominated Reference correspond to the state-of-the-art's methodology. On the other hand, columns called Model correspond to the results obtained making use of the methodology presented in this paper. It is possible to see that the new methodology improves accuracy with respect to the one of the reference model.

\subsection{Sensitivity analysis}

In this section, a sensitivity analysis has been performed to show the robustness of the obtained results. The idea is to vary the value of each parameter obtained through the optimisation process and to study the changes in the determination coefficient compared with the experimental results. The most important magnitude to analyse is the intensity of direct current, represented in Fig. 9, because it will drive battery consumption. Thus, for each of the eight parameters that make up the model, variations of $10 \%$ upward 
Table 3. $R^{2}$ for estimations of direct current intensity for the $8 x 6$ E propeller through the proposed methodology but varying the optimum parameters in a $10 \%$ upward and $10 \%$ downward; the reference determination coefficient obtained for the optimum values is 0.96297

\begin{tabular}{lcc}
\hline Parameter & Downwards perturbation & Upwards perturbation \\
\hline$K_{E}$ & 0.7918 & 0.9220 \\
$R$ & 0.957 & 0.9614 \\
$K_{\eta I}$ & 0.9362 & 0.9624 \\
$K_{n \omega}$ & 0.9587 & 0.9599 \\
$K_{\eta 0}$ & 0.9358 & 0.8691 \\
$K_{Q}$ & 0.8999 & 0.7997 \\
$K_{r}$ & 0.9622 & 0.9370 \\
$Q_{0}$ & 0.9502 & 0.9611 \\
\hline
\end{tabular}

Table 4. Skywalker X8 characteristics

\begin{tabular}{llc}
\hline Parameter & Units & Value \\
\hline$E M[40]$ & $\mathrm{kg}$ & 2.200 \\
$M T O M[40]$ & $\mathrm{kg}$ & 4.200 \\
$C_{D O}[41]$ & - & 0.0197 \\
$C_{D \alpha 1}[41]$ & $1 / \mathrm{rad}$ & 0.0791 \\
$C_{D \alpha 2}[41]$ & $1 / \mathrm{rad}^{2}$ & 1.060 \\
$C_{L O}[41]$ & - & 0.0867 \\
$C_{L \alpha}[41]$ & $1 / \mathrm{rad}$ & 4.02 \\
$\alpha_{\text {stall }}[41]$ & $\mathrm{o}$ & 17 \\
$S_{w}[41]$ & $\mathrm{m}^{2}$ & 0.750 \\
\hline
\end{tabular}

and downward are performed. After that, the corresponding determination coefficients for propeller $8 \times 6 \mathrm{E}$, in terms of direct current intensity, are included in Table 3. The results show that most of the variations keep the determination coefficient at acceptable levels, over 0.90, considering that the starting correlation coefficient is 0.96297 . The variables that are more sensitive to perturbations are $K_{E}, K_{\eta 0}$ and $K_{Q}$. On the other hand, $R$ and $Q_{0}$ are the most robust parameters.

\subsection{Case Study}

This section is designed to show how to perform the selection of an electric powerplant of a commercial RPAS called Skywalker X8. Table 4 includes all the necessary data to carry on this study [40-42], and Fig. 10 shows the plan view of the aircraft. The objective is to study several combinations of motors and propellers that allow the aircraft to fly in cruising conditions at a certain speed. Among them, the one with highest endurance will be chosen.

The empty mass, EM, includes structure, servos, an AXI2820/12 motor and an APC 12x6E propeller. Thus, if another powerplant is chosen, it will be necessary to update the empty weight of the RPAS according to the weight of its elements. In addition, it is going to be assumed that the MTOM of the aircraft is independent of the powerplant. This hypothesis is based on the launching and recovery system. The RPAS is launched through the aid of a bungee and it has recovery as a normal fixed wing aircraft. Therefore, the power capacity of the powerplant just affects the rate of climbing after taking off. Because of that, as first approximation, it is to be supposed that all the combinations can develop this flight. After the selection process, this hypothesis will be checked. The battery will supply a reference voltage of 


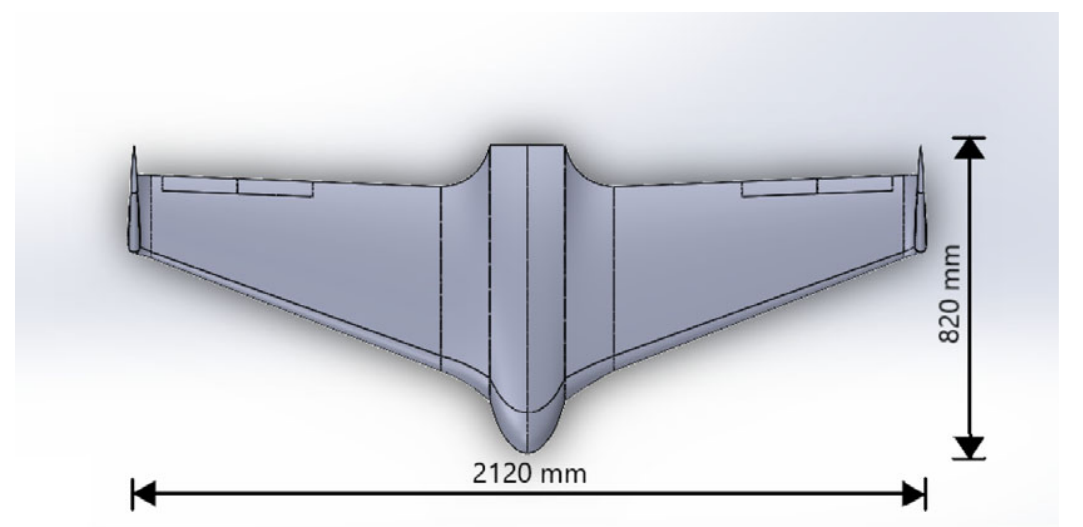

Figure 10. Plan view and general dimensions of Skywalker X8.

$14.8 \mathrm{~V}(4 \mathrm{~S})$, it will have a capacity of $10,000 \mathrm{mAh}$ with a mass of $842 \mathrm{~g}$ [43]. Attending to the available weight until reaching $M T O M$, two batteries can be installed. So, the final weight will be the addition of the updated $E M$ plus the batteries' weight. In order to build the model, it is going to work with a supplied voltage of $14.2 \mathrm{~V}$, to take into account that the voltage comes down while the battery is giving high current. Furthermore, the capacity of the batteries will be reduced by $10 \%$, to take into account the power consumption of other onboard equipment. The three motors considered in this study are those indicated in Table 1. Furthermore, several propellers are selected from Illinois' database compatible with those BLDC motors. The goal is to estimate how much time the RPAS can fly in steady cruising conditions for each combination of motor and propeller. According to the manufacturer, the cruising speed to perform a typical mission is $65 \mathrm{~km} / \mathrm{h}$.

The first step in this process is to know if each propeller can develop the necessary thrust to perform a steady cruising flight at $65 \mathrm{~km} / \mathrm{h}$ for X8 aircraft. Figure 11 depicts the intersection between a surface defined by the necessary power, which is the product of drag and speed, and a surface defined by the available power of propeller APC11 $8.5 \mathrm{E}$, which is the product of thrust and speed. It is possible to see that the necessary power to perform this flight does not depend on the angular velocity of the propeller, obviously. On the other hand, available power depends on angular velocity and aircraft speed. The intersection curve represents the points where that propeller can give the necessary power to develop the flight. Once this set of points has been determined, for each of them torque can be determined. This magnitude, together with angular velocity, are the input data necessary for the methodology presented in this paper. Following it for each operation point, it is possible to reach the direct current consumption of each motor. In case of motor AXI2820/12, Fig. 12 shows these results for several propellers. In this graph, the propeller with maximum endurance will correspond to the one with minimum current consumption at $65 \mathrm{~km} / \mathrm{h}$. In this case, the selected propeller would be APC $11 \times 8.5 \mathrm{E}$. Final endurance can be estimated just dividing battery capacity and the corresponding direct current.

This process must be followed for the three motors considered in this study. Comparing all the results, the operation point will be that which lowers current consumption at $65 \mathrm{~km} / \mathrm{h}$, which is, the highest endurance. Among the options considered in this case study, the best option corresponds to APC $11 \times 8.5 \mathrm{E}$ propeller and AXI 2820/12 motor, included in Table 4. In addition, the selected powerplant can develop a climbing flight after taking-off of $5^{\circ}$ at $65 \mathrm{~km} / \mathrm{h}$, which supposes a battery consumption of $2 \%$ of the battery capacity. This has been checked updating the necessary power to the level corresponding to the one used in performing the climbing flight. After that, the process followed to estimate the energy consumption in this condition is the same as the one followed for cruising. Analogously, a descent flight of $5^{\circ}$ at $65 \mathrm{~km} / \mathrm{h}$ has been analysed. The results obtained for both climbing and descent are included in Table 5, and schema of the flight profile is showed in Fig. 13. Considering these two extra consumptions, 


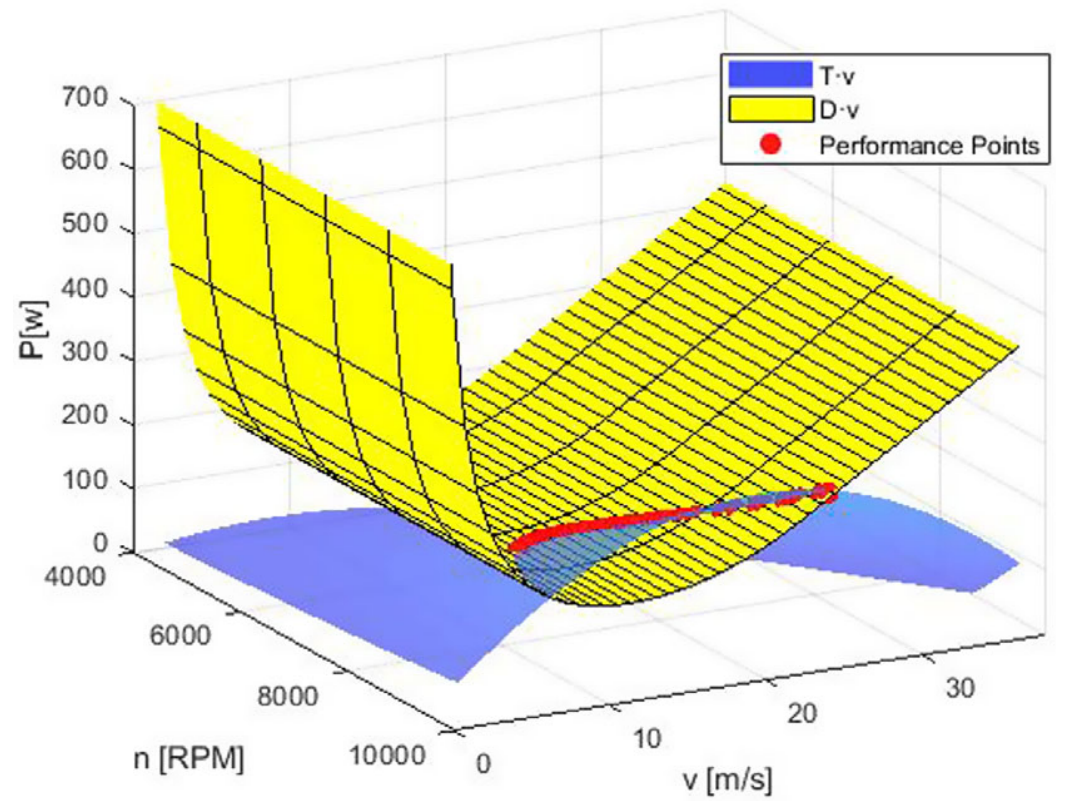

Figure 11. Necessary power, $D \cdot V$, versus available power, $T \cdot V$, for steady cruising flight of Skywalker $X 8$ with a propeller of APC $11 \times 8.5$.

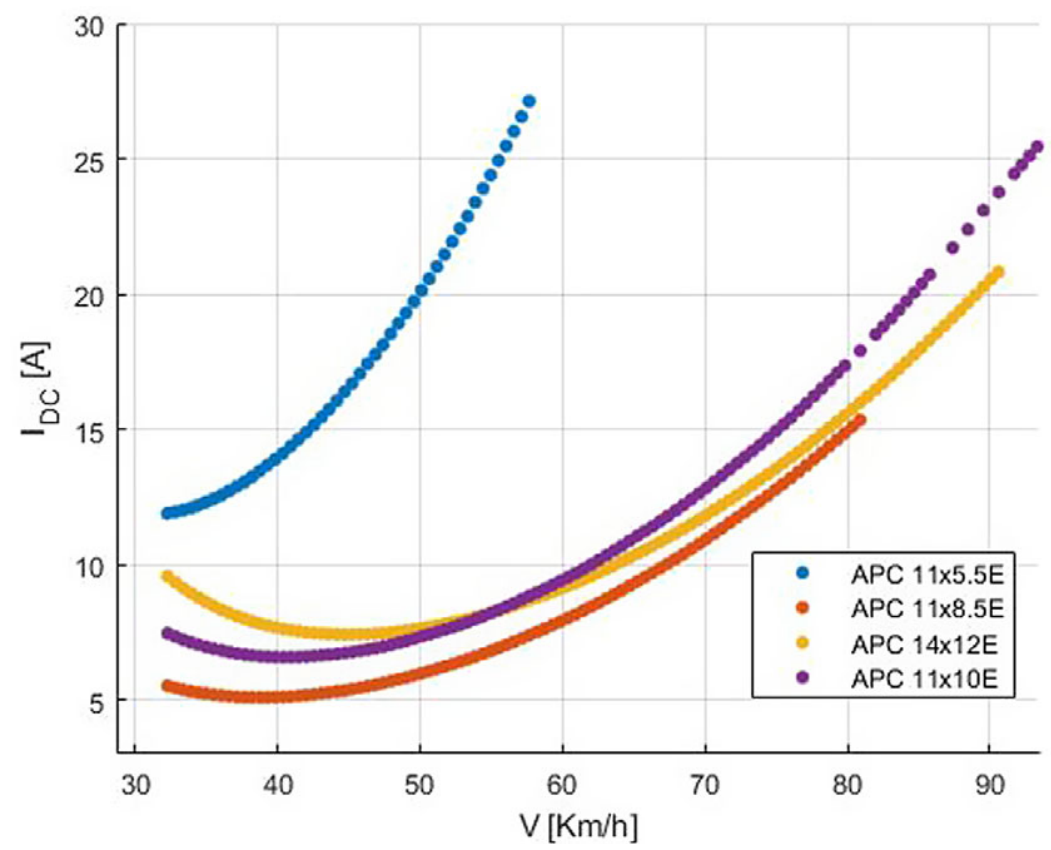

Figure 12. Current consumption versus angular velocity for steady cruising flight of Skywalker X8 with several propellers and motor AXI2820/12. 
Table 5. Results for a flight profile of motor AXI2820/12 and propeller APC11 1x8.5

\begin{tabular}{llccc}
\hline Parameter & Units & Climbing phase & Cruising phase & Descent phase \\
\hline$n$ & RPM & 7,557 & 6,213 & 4,159 \\
$V$ & $\mathrm{~km} / \mathrm{h}$ & 65 & 65 & 65 \\
$T \cdot V$ & $\mathrm{~W}$ & 120.97 & 66.87 & 1.21 \\
$Q$ & $\mathrm{~N} \cdot \mathrm{m}$ & 0.221 & 0.138 & 0.017 \\
$I_{A C}$ & $\mathrm{~A}$ & 20.72 & 12.59 & 0.764 \\
$V_{\text {Phase }}$ & $\mathrm{V}$ & 3.80 & 3.02 & 1.84 \\
$I_{D C}$ & $\mathrm{~A}$ & 18.09 & 9.29 & 0.38 \\
\hline
\end{tabular}

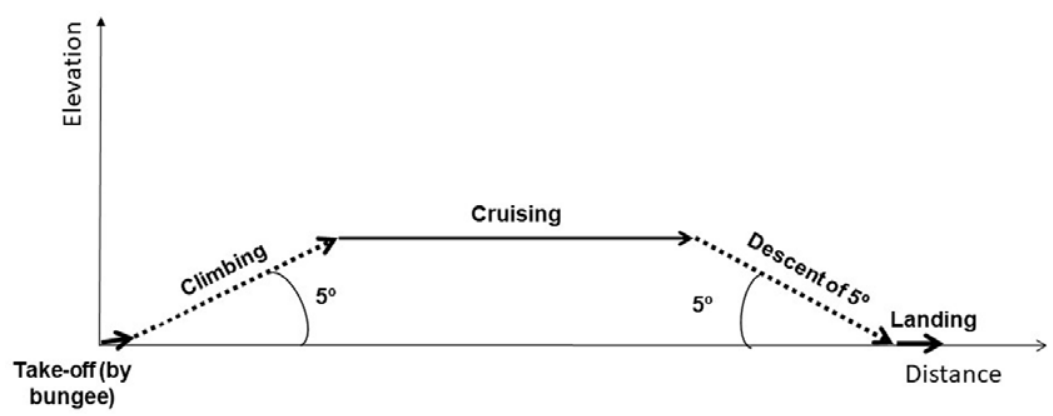

Figure 13. Flight profile of the studied mission for Skywalker X8.

the final endurance is $116 \mathrm{~min}$. The manufacturer declares that this aircraft has an endurance of, at least, $180 \mathrm{~min}$, but the cruising speed is not revealed. If cruising speed is chosen imposing the condition of maximum endurance, which corresponds to $39 \mathrm{~km} / \mathrm{h}$, the level reached with the proposed methodology grows until it reaches $206 \mathrm{~min}$. Thus, these results are fully compatible with the specifications given by the manufacturer and validate the methodology presented in this work.

This procedure shows how several powerplants can be easily compared in order to select the best option in terms of endurance for performing cruising flight. Of course, the procedure can analogously be repeated if the objective function or the mission changes, for example maximising range.

\subsection{Conclusions}

This paper presents a methodology to estimate the battery consumption of a BLDC electric powerplant, usually employed in light drones. This methodology tries to solve problems related to the accuracy of the data provided by manufacturers. Furthermore, the proposed method has the flexibility to predict the battery consumption if any element of the powerplant changes, for instance, propeller or battery voltage. The results show that the accuracy in terms of battery consumption is very high. In addition, the estimation of the internal magnitudes which appear in the model is more accurate than that given by other models found in the open literature. The strategy followed to reach the values of the parameters involved in the method has the advantage of absorbing errors associated with measurement taken for the internal magnitudes. On the other hand, these inaccuracies mean that the values of the parameters could not be so real. Because of that, it is not possible to compare their values with those reached through other methods. But, if direct current measuring is accurate enough, the prediction of the model is also precise.

Once the methodology has been demonstrated to be applicable, it will be necessary to update the test bench in order to perform the measurements in an automatic way. Furthermore, this updating should include equipment that allows measurement of the propeller's torque. Thus, it will not be necessary to use wind tunnel tests to extrapolate propeller's torque. Consequently, the set of propellers and motors 
that are suitable to be tested will be wider. This wider study may open another research line that consists of correlating the results obtained through testing with those reached with models based on manufacturer's data. This comparative study, performed for many motors, could reveal if an accurate estimation of battery consumption can be reached just by correcting the results given by the model based on manufacturer's data. Additionally, it would be desirable to analyse if it is possible to reduce the number of testing points without losing accuracy in the methodology. Finally, it will be desirable to analyse the effect of temperature on the discharge rate of the battery, in order to reach even a more accurate methodology.

\section{References}

[1] Commercial drones: global market size 2018 \& 2024, Statista Research Department, 2020.

[2] Wagner, I. Unmanned Aerial Vehicles - Global Market Size 2018 \& 2029, Statista, 2020.

[3] Provost, E.J., Butcher, P.A., Coleman, M.A. and Kelaher, B.P. Assessing the viability of small aerial drones to quantify recreational fishers, Fisher Manage Ecol, 2020, 27, pp 615-621. https://doi.org/10.1111/fme.12452.

[4] Pallottino, F., Figorilli, S., Cecchini, C. and Costa, C. Light drones for basic in-field phenotyping and precision farming applications: RGB tools based on image analysis, Methods Mol Biol (Clifton, NJ), 2021, 2264, pp 269-278. https://doi.org/10.1007/978-1-0716-1201-9_18.

[5] Ponte, S., Ariante, G., Papa, U. and Del Core, G. An embedded platform for positioning and obstacle detection for small unmanned aerial vehicles, Electronics, 2020, 9, https://doi.org/10.3390/electronics 9071175.

[6] Hyun, C.-U., Park, M. and Lee, W.Y. Remotely Piloted Aircraft System (RPAS)-based wildlife detection: A review and case studies in maritime Antarctica, Animals, 2020, 10, https://doi.org/10.3390/ani10122387.

[7] Eugenio, F.C., Schons, C.T., Mallmann, C.L., Schuh, M.S., Fernandes, P. and Badin, T.L. Remotely piloted aircraft systems and forests: A global state of the art and future challenges, Can J For Res, 2020, 50, (8), pp 705-716. https://doi.org/10.1139/cjfr-2019-0375.

[8] Miguel Gomez-Lopez, J., Luis Perez-Garcia, J., Tomas Mozas-Calvache, A. and Delgado-Garcia, J. Mission flight planning of RPAS for photogrammetric studies in complex scenes, ISPRS Int J Geo-Informat, 2020, 9, https://doi.org/10.3390/ijgi9060392.

[9] Filippone, A. and Barakos, G.N. Rotorcraft systems for urban air mobility: A reality check, Aeronaut J, 2021, 125, pp 3-21. https://doi.org/10.1017/aer.2020.52.

[10] FAA, Summary of Small Unmanned Aircraft Rule (Part 107), 2016.

[11] European Commission, Commission Implementing Regulation (EU) 2019/947 of 24 May 2019 on the rules and procedures for the operation of unmanned aircraft. Off J Euro Union, L, 2019, pp 45-71.

[12] Porthault, H., Calberg, C., Amiran, J., Martin, S., Paez, C., Job, N., Heinrichs, B., Liquet, D. and Salot, R. Development of a thin flexible Li battery design with a new gel polymer electrolyte operating at room temperature, J Power Sour, 2021, 482, https://doi.org/10.1016/j.jpowsour.2020.229055.

[13] Li, L., Wang, C., Yan, S. and Zhao, W. A combination state of charge estimation method for ternary polymer lithium battery considering temperature influence, J Power Sour, 2021, 484, https://doi.org/10.1016/j.jpowsour.2020.229204.

[14] Huang, H. and Savkin, A.V. Energy-efficient autonomous navigation of solar-powered UAVs for surveillance of mobile ground targets in urban environments, Energies, 2020, 13, https://doi.org/10.3390/en13215563.

[15] Chang, K., Rammos, P., Wilkerson, S.A., Bundy, M. and Gadsden, S.A., LiPo Battery Energy Studies for Improved Flight Performance of Unmanned Aerial Systems. In R. Karlsen, D. Gage, C. Shoemaker and G. Gerhart (eds.), Conf. Unmanned Syst. Technol. XVIII (Baltimore, 20-21 April, 2016). https://doi.org/10.1117/12.2223352.

[16] McCrink, M.H. and Gregory, J.W. Blade element momentum modeling of low-reynolds electric propulsion systems, J Aircr, 2017, 54, pp 163-176. https://doi.org/10.2514/1.C033622.

[17] Brandt, J.B., Deters, R.W., Ananda, G.K. and Selig, M.S. UIUC Propeller Database. University of Illinois at UrbanaChampaign, (n.d.). http://m-selig.ae.illinois.edu/props/propDB.html (accessed February 1, 2021).

[18] Dantsker, O.D., Caccamo, M., Deters, R.W. and Selig, M.S. Performance testing of aero-naut CAM folding propellers, AIAA Aviat 2020 Forum, 2020, 1 PartF, pp 1-52. https://doi.org/10.2514/6.2020-2762.

[19] Podsędkowski, M., Konopiński, R., Obidowski, D. and Koter, K. Variable pitch propeller for UAV-experimental tests, Energies, 2020, 13, pp 1-16. https://doi.org/10.3390/en13205264.

[20] Green, C.R. and McDonald, R.A. Modeling and test of the efficiency of electronic speed for brushless DC motors, 15th AIAA Aviation Technology, Integration, and Operations Conference, 2015. https://doi.org/https://doi.org/10.2514/6.2015-3191.

[21] Gong, A. and Verstraete, D. Experimental testing of electronic speed controllers for UAVs, 53rd AIAA/SAE/ASEE Joint Propulsion Conference, 2017. https://doi.org/10.2514/6.2017-4955.

[22] Nise, N.S. Control System Engineering. Sixth Edition. John Wiley \& Sons, Inc., Jefferson City, 2011.

[23] Bachiller-Soler, A., García-López, F.D.P. and Cano-González, R. Design of an automated test bench for brushless motors, Electric Technol Eng, 2011, 86, pp 418-423. https://doi.org/https://doi.org/10.6036/4019.

[24] Achtelik, M.C., Doth, K.M., Gurdan, D. and Stumpf, J. Design of a multi rotor MAV with regard to efficiency, dynamics and redundancy, AIAA Guidance, Navigation, and Control Conference, 2012, pp 4-7. https://doi.org/10.2514/6.2012-4779. 
[25] Adamo, F., Andria, G., Di Nisio, A., Calò Carducci, C.G., Lay-Ekuakille, A., Mattencini, G. and Spadavecchia, M. Designing and prototyping a sensors head for test and certification of UAV components, Int J Smart Sens Intell Syst, 2017, 10, pp 646672. https://doi.org/10.21307/ijssis-2017-228.

[26] Gundlach, J., Designing Unmanned Aircraft Systems: A Comprehensive Approach, First edition. AIAA Education Series, Manassas, Virginia, 2013.

[27] Persson, C. Drive Calculator, 2010. http://www.drivecalc.de/ (accessed February 1, 2021).

[28] Schenk, H. Propeller Calculator, 2010. http://www.drivecalc.de/PropCalc/index.html (accessed February 1, 2021).

[29] Mueller, A.M., eCalc. (n.d.). https://www.ecalc.ch/ (accessed February 1, 2021).

[30] Sartori, D. and Yu, W. Experimental characterization of a propulsion system for multi-rotor UAVs, J Intell Robot Syst Theory Appl, 2019, 96, pp 529-540. https://doi.org/10.1007/s10846-019-00995-2.

[31] Kotarski, D., Krznar, M., Piljek, P. and Simunic, N. Experimental identification and characterization of multirotor UAV propulsion, J Phys Conf Ser, 2017, 870, https://doi.org/10.1088/1742-6596/870/1/012003.

[32] Piljek, P., Kotarski, D., Krznar, M. Method for characterization of a multirotor UAV electric propulsion system, Appl Sci, 2020, 10, https://doi.org/10.3390/app10228229.

[33] Stepaniak, M.J., Van Graas, F. and De Haag, M.U. Design of an electric propulsion system for a quadrotor unmanned aerial vehicle, J Aircr, 2009, 46, pp 1050-1058. https://doi.org/10.2514/1.38409.

[34] Sekalala, S. Performance of A Three-Phase Permanent Magnet Motor Operating as A Synchronous Motor and A Brushless DC Motor, Louisiana State University, 2006.

[35] Vu, N.A., Dang, D.K. and Le Dinh, T. Electric propulsion system sizing methodology for an agriculture multicopter, Aerosp Sci Technol, 2019, 90, pp 314-326. https://doi.org/10.1016/j.ast.2019.04.044.

[36] Levenberg, K. A method for the solution of certain nonlinear problems in least squares, Q J Appl Math, 1944, 2, pp 164-168.

[37] Marquardt, D.W. An algorithm for least-squares estimation of nonlinear parameters, J Soc Ind Appl Math, 1963, 11, pp 431441.

[38] Wilson, P. and Mantooth, H.A. Chapter 10 - Model-based optimization techniques. In P. Wilson and H.A. Mantooth (eds.), Model Eng Complex Electron Syst, Newnes, Oxford, 2013, pp 347-367. https://doi.org/10.1016/ B978-0-12-385085-0.00010-5.

[39] Mason, R.L., Gunst, R.F. and Hess, J.L. Statistical Design and Analysis of Experiments, Second edition. Wiley-Interscience, Hoboken, New Jersey, 2003.

[40] Gryte, K., Hann, R., Alam, M., Rohac, J., Johansen, T.A. and Fossen, T.I. Aerodynamic modeling of the skywalker X8 fixed-wing unmanned aerial vehicle, 2018 International Conference on Unmanned Aircraft Systems, ICUAS 2018, 2018, pp 826-835. https://doi.org/10.1109/ICUAS.2018.8453370.

[41] Airelectronics, X8 Flying Wing. (n.d.). http://www.hobbyking.com/hobbyking/store/uh_viewitem.asp?idproduct=27132 (accessed February 18, 2021).

[42] Winter, A., Hann, R., Wenz, A., Gryte, K. and Johansen, T.A. Stability of a flying wing uav in icing conditions, 8th European Conference for Aeronautics and Aerospace Sciences (EUCASS). June, 2019. https://doi.org/10.13009/EUCASS2019-906.

[43] RC Innovations. (n.d.). https://rc-innovations.es/u-tech-pro-10000mah-4s-14.8v-15c-lipo-battery.

Cite this article: Rodríguez-Novillo E. and Sanchez-Carmona A. (2022). Battery consumption estimation methodology for electric unmanned aerial systems. The Aeronautical Journal, 126, 1527-1545. https://doi.org/10.1017/aer.2022.7 